\title{
LA COMPOSICIÓN POÉTICA DE LOS PERSONAJES INDÍGENAS FEMENINOS EN LA LITERATURA LATINOAMERICANA: XICOTÉNCATL (1826) E IRACEMA (1865) ${ }^{1}$
}

\author{
THE POETICAL COMPOSITION OF AUTOCTONOUS FEMALE CHARACTERS \\ IN LATIN AMERICAN LITERATURE: \\ XICOTÉNCATL (1826) AND IRACEMA (1865)
}

\section{Leila Shaí Del Pozo González² Francisco Lima Baca ${ }^{3}$}

Resumen: Este estudio presenta el personaje femenino de extracción histórica Malinche, o doña Marina, y la puramente ficcional Teutila, en Xicoténcatl (1826) - obra cuya autoría todavía es discutida por muchos estudiosos - y el personaje femenino protagonista de Iracema (1865), de José de Alencar - obra que se encuadrada dentro de las producciones del romanticismo brasileño - con el objetivo de establecer paralelos y diferencias adjudicados a estos personajes dentro de las literaturas en formación: Brasil y México, como literaturas base generadoras de la idea de nación en sus respectivos contextos.

Palabras claves: Malinche, Teutila e Iracema; personajes indígenas femeninos de la literatura latino-americana del siglo XIX; literatura y nación; Xicoténcatl (1826) e Iracema (1865).

Abstract: This study introduces the female character of historical extraction Malinche, or doña Marina, and, the fully fictional one, Teutila, in Xicoténcatl (1826) - which authorship is still discussed by many scholars - and the main and female character of Iracema (1865), by José de Alencar - a work framed inside the Brazilian romantic production. The paper aims to establish parallels and differences awarded to the mentioned characters in the developing literature of Brazil and Mexico, as ground pieces of literature generators of the idea of nation in its respective contexts.

\footnotetext{
${ }^{1}$ Parte del texto analítico es producto de la tesis de doctorado en Estudios Latinoamericanos, La representación poética del indígena en tres novelas latinoamericanas: Netzula, de José María Lacunza; , de José de Alencar y Aves sin nido, de Clorinda Matto de Turner" (2015), de Francisco Lima Baca y de la disertación de maestría en Letras, Malinche no espelho das traduções de Xicoténcatl (1826): [1999-2013] (2017), de Leila Shaí Del Pozo González. Ambos integran el grupo de investigación "Ressignificações do passado na América Latina: leitura, escrita e tradução de gêneros híbridos de história e ficção - vias para a descolonização", liderado por el Prof. Dr. Gilmei Francisco Fleck.

2 Posee maestría por el programa de pos graduación en Letras - Universidad Estatal del Oeste del Paraná/UNIOESTE. Estudiante del Doctorado en el mismo programa de pos graduación en Letras. Profesora colaboradora del área de letras español en la UNIOESTE/Cascavel-PR), bajo la orientación del doctor Gilmei Francisco Fleck. E-mail: leilashai@hotmail.com.

${ }^{3}$ Licenciado, Maestro y Doctor en Estudios Latinoamericanos, formado en la Universidad Nacional Autónoma de México/UNAM. Becario de Posdoctorado de la Universidade Estadual de Feira de Santana/UEFS Departamento de Letras de Artes. Programa de Pós-graduação em Estudos Literários. Programa Nacional de Pós-doutorado (PNPD/CAPES), bajo la orientación del doctor Claudio Cledson Novaes. E-mail: flimaba@gmail.com
} 
Keywords: Malinche, Teutila and Iracema; autoctonous female characters of the Latin American literature of the nineteenth century; literature and nation; Xicoténcatl (1826) and Iracema (1865).

\section{Introducción}

Los protagonistas femeninos de las novelas Xicoténcatl ${ }^{4}$ (Malinche y Teutila) e Iracema (Iracema) establecen puntos de encuentro y de diálogo a partir de sus composiciones poéticas. En el caso de la novela Xicoténcatl (1826), los personajes indígenas encarnan el imaginario social de una identidad nacional idealizada, representando en las acciones de los personajes, valores morales, éticos y civiles que configuran los modelos de conducta de una sociedad en formación.

De forma particular, el personaje femenino de extracción histórica Malinche, o doña Marina, nombre utilizado en la narrativa en cuestión, por el contexto histórico descrito en el proceso de conquista, configura, a partir de la ficción literaria, el choque, el encuentro, el diálogo y el inicio de la muerte del mundo indígena por sometimiento ante una cultura que trajo la escritura como una de sus armas colonizadoras más poderosas.

De ahí que Malinche, como personaje literario de extracción histórica, cumpla un papel fundamental en Xicoténcatl, una de las primeras narrativas ficcionales históricas ${ }^{5}$ de México, Latinoamérica y en lengua española ya que, en el año de 1832 y de 1837 fueron publicadas las obras: Netzula, atribuida a José María Lacunza, y La Batalla de Otumba, ambas obras consultadas en la edición facsimilar de la publicación decimonónica de El Año Nuevo.

En las dos novelas, al igual que en Xicoténcatl, se reinterpretan los acontecimientos que marcaron de forma significativa el devenir del contexto mexicano, con la diferencia de

\footnotetext{
${ }^{4}$ Tanto la obra como el personaje son conocidos por diversas grafías, como: Sicutengal, Jicoténcatl, Jicoténcal, Xicotenga, entre otros, etc. (DEL POZO GONZÁLEZ, 2017). Leal y Cortina (1994) adoptan Jicoténcal en su edición de la obra. Como en la edición de 1964 de Castro Leal y de 2012 de Forero Quintero, en este estudio decidimos utilizar la grafía Xicoténcatl para coincidir con el título de la publicación de la obra en portugués que se encuentra en trabajos de edición.

${ }^{5} \mathrm{Al}$ referirnos a las novelas ficcionales históricas en donde los indígenas son los personajes centrales es fundamental hacer referencia de la obra: La Novela Indianista en Hispanoamérica (1832 - 1889) de Concha Meléndez. En dicho texto la autora desarrolla un análisis histórico respecto a la manera en que el indígena ha sido representado a partir de las crónicas de conquista y, de manera especial, en las obras literarias del siglo XIX en donde el mismo se torna un personaje central al encarnar valores cívicos de las sociedades que surgieron tras el proceso de independencia.
} 
que, en el caso de Netzula la narrativa, descrita de una forma general, se enfoca en la concepción poética romántica de una virgen indígena que se apasiona por un guerrero, el cual, muere en la batalla final contra los conquistadores y, en lo que respecta a La Batalla de Otumba, atribuida a Eulalio Ortega, se relata de una manera mucho más profunda y concisa, una de las batallas que marcaron la derrota de las antiguas culturas indígenas en contra de los españoles.

Ambas novelas, Netzula y La Batalla de Otumba, muestran el interés de reinterpretar, a partir de la reconfiguración de una novela histórica, la lucha de conquista, exaltando valores morales, éticos y civiles que ejemplifiquen, a las nuevas clases sociales surgidas tras el proceso de independencia, la idea de una ciudadanía y los valores que deben ser referencia de la misma. Ahora bien, la diferencia fundamental en relación a la novela Xicoténcatl es que en dicha obra se crea, a diferencia de las anteriores, una suerte de tesis que explica el nacimiento de la nación mexicana, simbolizado en la trama por medio del nacimiento del hijo mestizo de Malinche y Cortés.

Por otro lado, se encuentra el único personaje puramente ficcional en la obra, Teutila, la compañera de Xicoténcatl, el joven. Creada para ser la única mujer digna del protagonista. Este personaje simboliza lo más valioso del mundo indígena: la belleza del continente americano, los valores autóctonos, el coraje de las mujeres, la resistencia a la ocupación europea. Es la perfección indígena personificada y su muerte en la narrativa significa que sería imposible continuar el mundo americano tal como antes de la llegada de los europeos.

En lo que respecta al contexto brasileño, Iracema (1865) se torna un interlocutor que dialoga de forma significativa con los procesos que precisaron la formación de una literatura nacional en la reinterpretación ficcional. El personaje Iracema, en este sentido, encarna la dimensión de una guerrera y sacerdotisa, de una mujer apasionada, de una madre y de una mártir, para especificar el proceso de conquista y encuentro que concretará, de acuerdo al proyecto literario de José de Alencar, una poética que puntualice la identidad de Brasil a partir de la reinterpretación de acontecimientos y de una configuración poética compleja, en donde, los valores éticos, morales y civiles, antes mencionados, permiten establecer un diálogo entre dos proyectos narrativos de formación de identidades en el siglo XIX en México y en Brasil.

\section{La novela Xicoténcatl (1826) y la idea de nación en Latinoamérica}


La América Latina está estrechamente vinculada a la civilización europea por medio de valores de pensamiento, ciencia, cultura, jurídica, política, entre otros (JOZEF, 2005). No se intentó negar esa tradición, sin embargo, la intelligentsia americana de entonces estaba dispuesta a iniciar una producción que se ubicase lejos de esa herencia, pues, desde el inicio de la colonización, los americanos, nacidos o trasplantados - es decir que se incluye a las "gentes que podían no tener en sus venas mezclada la sangre de los pueblos del encuentro, pero que llevaban en su espíritu la creadora confluencia de vertientes contrarias" (USLAR PIETRI, 1985) - en este continente, se sintieron, o los hicieron sentirse, diferentes de los europeos.

De forma específica, respecto a la formación de una intelligentsia americana, José Luis Romero, en el prólogo del libro: Pensamiento Político de la Emancipación, define una categoría fundamental para entender, tanto las cuestiones identitarias como las que conforman un proyecto literario: "patrias bobas". Las llamadas "Patrias bobas", siguiendo la reflexión del autor, son todas aquellas naciones que, tras el proceso de independencia buscan de forma constante el ser modernas a partir de una autonomía de carácter política, cultural y económica, siguiendo los patrones de civilidad y de modernidad de carácter europeo, mas, buscando en los mismos crear su propia originalidad, o camino, para, de esta manera, ser independientes tanto en cuestiones políticas como económicas.

En este sentido, la literatura será una herramienta que legitime esa intelligentsia americana, pues, el carácter ideológico que estará inserido en el discurso de las obras y en la concepción poética de las mismas, mostrará la complejidad histórica, cultural, social y política que será el reflejo de las mismas, y que, por tanto, creará una literatura original y de carácter propiamente nacional.

De acuerdo a Henríquez Ureña (s.d. [1925], p. 180) la tardía producción de novelas en la América española fue el resultado de leyes - entre 1532 y 1543 - que prohibían la circulación, lectura e impresión de

[...] obras de imaginación pura, en prosa o en verso ('que ningún español o indio lea... libros de romances, que traten materias profanas y fabulosas, e historias fingidas, porque se siguen muchos inconvenientes') y se ordenó que las autoridades no permitiesen que se imprimieran o se trajeran de Europa. 
Este sería el motivo por el cual, solo a partir del decreto IX de libertad de imprenta de las Cortes de Cádiz, finalmente se publicase la primera novela mexicana y latinoamericana, $E l$ Periquillo Sarniento (1816), de José Joaquín Fernández de Lizardi. Los años que contextualizan este suceso son los años de lucha por la independencia de las colonias españolas en el continente americano.

Por consiguiente, la novela Xicoténcatl (1826) también se encuentra en este período pro independentista. Su producción está lejos del periodo estudiado como el Neoclásico, sin embargo no se pueden negar sus fuertes raíces, aunque debemos mencionar, también, que estaría dentro de las primeras producciones que podrían ser catalogadas como del romanticismo latinoamericano.

Así, como en el caso de la obra mencionada de Lizardi, Xicoténcatl (1826) fue escrita para las grandes masas ignorantes, a manera de educarlos para que entiendan la necesidad de participar en los movimientos por la independencia. El estudioso Gustavo Forero Quintero (2012), inclusive le adjudica a la obra Xicoténcatl (1826) la tesis del "destino manifiesto" de la nación americana y el destino heroico de la nación mexicana. Desde esa perspectiva, este investigador indica que el narrador en la novela de 1826 se expresa con un tono de preocupación con respecto a las colonias españolas frente a Europa y los Estados Unidos.

Debido a todos esos aspectos, la narrativa en Xicoténcatl (1826) muestra el imaginario social de una identidad nacional idealizada, donde los europeos, en general son los villanos, encabezados por Cortés, y los indígenas son miembros de una sociedad con tintas de república, con senado y leyes, características que no podrían ser adjudicadas en la construcción ficcional de una novela europea de la época para una sociedad nativa, ya que el mundo indígena fue visto con inferioridad por los colonizadores.

En virtud de ello, los personajes principales indígenas son configurados como los buenos, encabezados por Xicoténcatl, el joven, el héroe apolíneo: joven, bello, valiente, fiel a su pueblo, devoto enamorado de su esposa Teutila y defensor de las costumbres indígenas, el mejor guerrero de Tlaxcala. En la hueste de Cortés, también encontramos indígenas que hacen el grupo de colaboradores del capitán extremeño. Entre estos personajes se encuentra Doña Marina, la Malinche.

\section{Iracema (1865): un proyecto de literatura nacional}


La novela Iracema (1865), de José de Alencar, forma parte del proyecto literario de dicho autor para entender y conocer Brasil a partir de su imagen literaria, es decir, desde su representación histórica, urbana, regional e indianista. Las novelas Ubirajara (1874), O Guarani (1857) e Iracema (1865) forman parte de la fase histórica e indianista, pues en ellas el autor desarrolla toda una serie de notas y de ensayos que reconfiguran el proceso de colonización así como la historia de las culturas indígenas.

En el libro con manuscritos inéditos Antiguidade da América e A raça primogénita ([1877] 2010), José de Alencar realiza una serie de anotaciones de carácter arqueológico, histórico y lingüístico, en donde muestra la instrumentalización del conocimiento para constituir una narrativa compleja en su proyecto literario. De ese modo, en Iracema (1865) se observa todo un estudio etimológico de palabras que, como declara el propio autor en la carta que se publica con la narrativa en la primera edición de la novela de 1865, ayudarían a la configuración más "viva" de los personajes indígenas en su novela, permitiendo acercar más al lector a la lengua - pues utiliza los regionalismos de base indígena -, al paisaje y a la atmósfera que contextualiza, permitiendo sentir la belleza del mundo indígena a través de las palabras, cuando menciona: "a beleza da expresssão selvagem em sua tradução literal $e$ etimológica" (ALENCAR, [1865] 2010, p. 106).

En dicha carta, el escritor defiende la importancia de escribir un proyecto de literatura nacional. Este menciona inclusive, que escribir Iracema (1865) sería un ensayo que reflejaría estas ideas (ALENCAR, [1865] 2010, p. 108). Si bien la carta referida es esencial para entender el proceso de creación literaria del autor, de igual forma el texto: Antiguidade de América e A raça primogénita ([1877] 2010), coloca, como punto fundamental, la noción ficcional que el autor utiliza para reinterpretar la historia antigua de las culturas indígenas que habitaban en Brasil durante el proceso de conquista de los portugueses.

De igual manera toda esta reconstrucción de carácter histórica, a su vez, es investigada de forma profunda por Mirhiane Mendes de Abreu en su obra: Ao pé da página. A dupla narrativa em José de Alencar (2011) en dicho texto, la autora señala que las notas al pie de página de la obra de José de Alencar son textos expositivos, de carácter histórico y político, que muestran el conocimiento y la propuesta literaria del autor, y, de forma particular, en sus novelas indianistas el novelista realiza toda una sustentación de carácter histórica, social, 
lingüística y arqueológica para desarrollar una veracidad más contundente y concisa que sustente su creación literaria.

Todas estas características hacen que esta obra sea un ejemplar dentro del conjunto de producciones del romanticismo latinoamericano, pues, como Lima Baca (2015, p. 17) señala, “el poeta romántico [latinoamericano] está imbuido en un proyecto político, el cual es el formar un proyecto de estado nuevo, joven, [...] en donde se dan los inicios de una historia y de una identidad nacional" y el texto que nos deja Alencar deja bastante claro ese aspecto.

De la misma forma que en Antiguidade da América e A raça primogénita ([1877] 2010), la edición facsimilar A Confederação dos Tamoios ([1856] 2007), de Gonçalves de Magalhães, coloca como parte de la obra las cartas que José de Alencar escribió como respuesta al autor, en las cuales, de una forma aguda, desarrolla una propuesta poética, en la cual, de acuerdo con Laianice Soares Adorno y Amanda Moura de Souza ${ }^{6}$, se desenvuelve una serie de categorías de carácter estético que define la propuesta de Alencar como una creación artística y literaria compleja.

Por otro lado, debemos destacar que Iracema (1865) es considerada como una de las obras del romanticismo latinoamericano, una estética distinta de la europea por traer consigo tanto el discurso político como la idea de concebir la identidad latinoamericana, sin con ello desvincularse en su totalidad de las concepciones ideológicas y políticas que buscan construir un proyecto, individual, propio, de estado (LIMA BACA, 2015).

Además, la obra Iracema (1865) estaría dentro de lo que Candido (1975, p. 368) entiende como la temática de la formación histórica de la colonia, "marcada por el contacto revitalizador entre portugués e indígena”. El autor ochocentista, para ello, decide escribir una novela de cuño histórico, con los personajes Martín Soares Moreno, Felipe Camarão y el líder indígena Jacaúna.

\section{Malinche: único personaje esférico en Xicoténcatl (1826)}

Como el propósito de la obra es demostrar la tesis que afirma que el mundo indígena fue grandioso y que la cultura impuesta corrompió a los nativos, la narrativa presenta a

\footnotetext{
${ }^{6}$ Laianice Soares Adorno y Amanda Moura de Souza presentaron en el evento: XVII SEMALET en la Universidade Estadual de Feira de Santana, el día 6 de diciembre de 2019, el trabajo titulado: Cartas resposta ao poema A Confederação dos Tamoios: uma analogia entre a proposta poética de José de Alencar e a poética europeia, en donde definen seis categorías para entender la complejidad del proyecto literario que José de Alencar desarrolló.
} 
Malinche como la única figura circular de la novela. En ella recae todo el proceso de vida y muerte del mundo indígena.

La narrativa inicia con una Malinche ingenua (primera fase), a la medida del "buen salvaje", cuando en la voz del personaje Ordaz, que critica la conducta de Cortés del modo siguiente: “[ [...] casi hace ostentación de sus amores adúlteros con esa india, quizá víctima de su seducción. [...]" (ANÓNIMO, 1964, p. 85). Ese trecho muestra al personaje, que desde su voz impoluta, mezclada con la voz narrativa, se permite dudar sobre lo que habría llevado a Malinche a tal situación. De esa forma, se abre la posibilidad de interpretar la conducta de Malinche como resultado de ella haber sido víctima de la seducción de Cortés.

En un segundo momento (segunda fase), la voz narrativa configura Malinche, de forma que se sugiere que, en la actividad de confidente, Malinche trajo grandes ventajas a Cortés, pues sus coterráneos no sospechaban en ella la corrupción aprendida con los europeos. Así, inicialmente, Malinche fue seducida y luego aprende a ser corrupta, comportándose como arma importante para Cortés.

El personaje de Malinche llega a ser configurado como la mujer pérfida, la intrigante, que llega a ofrecerse a Ordaz: “[...] Difícil sería querer pintar la sorpresa del honrado español al oír la libre declaración de amor que le hizo doña Marina. Esta le dijo que, esclava y no amante de Hernán Cortés, aborrecía su soberbia y dominación [...]” (ANÓNIMO, 1964, p. 101), después de afirmar que Cortés la había elegido por "sus buenos talentos y las gracias" (ANÓNIMO, 1964, p. 99) que inmediatamente después de bautizarla "con el nombre de Marina, puso en ella su amor y su confianza, de manera que en pocos días pasó de su esclava a su concubina y confidenta.” (ANÓNIMO, 1964, p. 99).

Además, en otro momento la narrativa muestra a Xicoténcatl furioso al percibir que Malinche no es una doncella como él pensaba (ella ya está embarazada) y lanza muchos adjetivos negativos en su rabia: “[...] - ¿Es posible, igran Dios! [...] es posible tanta perfidia, y tanta doblez, y tanta falsedad, y tanto arte, y tanta infamia? Esa americana indigna, [...] ¿Quién hubiera podido descubrir el veneno de sus dulces palabras?" (ANÓNIMO, 1964, p. 117). Este sería el inicio del mito de Malinche (HERREN, 1993), como la mujer traidora, corrupta, la prostituta del imaginario colectivo del pueblo mexicano.

De ese modo, Marina se muestra como el ser corrompido, seductor, degradado, al servicio de hombres que la utilizan como un objeto para alcanzar objetivos políticos 
determinados y, en los encuentros descritos, entre los personajes que defienden los valores de una nación. En esta parte de la narrativa, se presenta la seducción como una herramienta para corromper y vencer una batalla

Y ya casi al finalizar la narrativa (tercera fase), Malinche, con los dolores de parto, se redime “[...] Yo soy una grande pecadora y es menester que todo el Universo conozca mis culpas [...] que el martirio que sufro sirva de ejemplo y de escarmiento a los que, como yo, abandonan la senda de la virtud. [...]. (ANÓNIMO, 1964, p. 139). Y vuelve a usar y creer en sus tradiciones nativas, porque: "[...] desde que fui cristiana, mis progresos en la carrera del crimen fueron más grandes que las hermosas virtudes de Teutila. [...]”. (ANÓNIMO, 1964, p. $153)$.

Como se puede observar, todos los trechos citados dibujan la circularidad con la que fue configurada Malinche en Xicoténcatl (1826). Esta característica sirve al propósito de demostrar que inclusive entre los que ayudaron a los españoles forman parte de la nueva nación que se forma, abrazando las buenas costumbres nativas.

\section{Dos personajes femeninos en Xicoténcatl: un proyecto de nación - el mito Malinche}

Al reflexionar sobre los personajes femeninos de dos novelas que configuran la historia de las culturas indígenas es pertinente concentrarse sobre el siguiente punto: el hecho de afirmar que en la novela Xicoténcatl (1826) "la narrativa presenta a Malinche como la única figura circular de la novela". Malinche, en tanto personaje literario, constituye el tránsito del proceso violento de conquista, al de redención ya que, dentro de la novela, la protagonista muestra, a partir de sus acciones y de su discurso, los motivos y las razones que la llevaron a corromperse, de la misma forma que las situaciones que la hacen evolucionar como un ente ${ }^{7}$ complejo, esférico ${ }^{8}$, que representa, como metáfora histórica, social y política, la "madre simbólica" de la nueva sociedad que surge tras el proceso de colonización.

\footnotetext{
${ }^{7}$ El concepto "ente", en la narrativa del siglo XIX tiene relación con la configuración plástica de la narrativa que recreo la naturaleza y los modelos literarios a partir de la historia y del teatro. De forma específica en las cartas que José de Alencar escribe en sus obras teatrales define dicho concepto al referirse a los personajes de sus obras literarias, de forma específica, a la novela en cuestión Iracema.

${ }^{8}$ E. M. Forster en su obra Aspectos de la novela señala que, debido a la complejidad de los personajes en las novelas, pueden ser caracterizados como esféricos o planos. Los personajes esféricos serán aquellos que, en el transcurso de la narración, muestren una evolución coherente y profunda, y los personajes planos o tipo, serán aquellos que formen parte de las acciones en la narrativa, pero que no tendrán esa complejidad que define la coherencia de los esféricos o redondos.
} 
Malinche, es esa "madre simbólica" en cuestiones específicas, históricas, que, tal como señalan autores como Samuel Ramos en su obra El perfil del hombre y la cultura en México ([1934] 2001), Octavio Paz en El laberinto de la soledad ([1950] 2005) y Roger Bartra en La jaula de la melancolía (1987) definieron el surgimiento de una identidad a partir del acto violento de la conquista de una cultura sobre otra, de dos mundos contrapuestos bajo procesos históricos, políticos y religiosos que, al "encontrarse", chocaron uno contra otro por sus cosmovisiones de tiempo, vida y cultura.

Malinche, como personaje literario de extracción histórica, recibe por primera vez una configuración literaria en Xicoténcatl (1826). Es a partir de la publicación de esta obra, según los estudios de Herren (1993), Cypess (2000) y Nevarez (2004), que el mito de Malinche es posible, gracias a parte del proceso configurado en la narrativa como "la activa colaboradora nativa de Cortés, la corrupta."

Cypess (2000, p. 43, 184) cita al historiador mexicano Edmundo O'Gorman que afirma que el uso de la figura literaria de la obra ochocentista, la configuración de "doña Marina", sirve de base para transformar al personaje histórico en un "chivo expiatorio" para justificar el desorden, la ruina económica y el caos administrativo del periodo pos independentista mexicano. Por otro lado, la figura de Magiscatzin, otro personaje de extracción histórica, el representante de la parte corrupta nativa, no obtiene ninguna sanción en el imaginario del pueblo mexicano.

Inclusive, de acuerdo con Cypess (2000, p. 49), en Xicoténcatl (1826) se gasta más tempo narrativo en la elaboración de la traición de Magiscatzin y los esfuerzos patriotas de los Xicotencatl, pues el objetivo de la voz narrativa es dejar claro los efectos malignos que una guerra civil puede traerle a la república.

Otra cuestión que refuerza este punto es la construcción del personaje Teutila, una figura plana que es totalmente ficcional y con el cual no se establecería una simple dialéctica con Malinche sino que se observa que este personaje surge para servir de parte complementaria para explicar la tesis del narrador.

Teutila, en la narración, encarna los altos valores cívicos de una sociedad moderna, ella es la virgen impoluta, la amante fiel, la servidora humilde de los líderes de una nación, el emblema femenino de la pureza autóctona que, inicialmente se perfila como estando en contraposición con la primera, Marina o Malinche, como una antítesis de sentido y de 
conducta. Así, mientras que doña Marina es el símbolo de la aceptación inmediata del conquistador y su cultura, Teutila es la representación de la resistencia indígena.

Sin embargo, el personaje Teutila no llega a ser madre. Su destino es no tener descendencia, pues esta no llega a tener hijos de su amado Xicoténcatl y se recusa a tenerlos con Cortés, o con cualquier otro personaje español - es decir, se niega a ser la madre del mundo mestizo - y, por eso, su destino es morir. Como se puede observar, la narrativa llega a demostrar que este personaje femenino deberá morir trágicamente antes de conseguir asesinar a Cortés para vengarse por la muerte de su esposo.

Y, de esta manera, con la muerte de Teutila, la narrativa poéticamente explica la necesaria muerte del mundo indígena, pues este modo de vida no podría continuar existiendo después de la "conquista". Sin embargo, debemos tomar atención a la cuestión de que este personaje "fracasa" al no conseguir dar muerte a Cortés. Así, ella también llevaría, en la narrativa, culpa por no haber evitado la "conquista", quitándole parte del peso de la "carga de la traición" al personaje Malinche por colaborar con Cortés (NEVAREZ, 2004).

Por consiguiente, al morir Teutila, Malinche se transforma en la única forma viable de continuar la vida en un mundo, nuevo, mestizo. La voz narrativa le concede el perdón a la arrepentida doña Marina, y esta, al dar a luz al hijo de Cortés, se convierte en la madre simbólica de la sociedad mestiza. De esta forma, a Malinche se le adjudican los símbolos de la madre fecunda que trae consigo la posibilidad de un nuevo mundo/futuro, madre de los mestizos. Una madre indígena que vuelve a valorizar las buenas costumbres indígenas y que al mismo tiempo acepta lo nuevo, lo extranjero.

\section{Relaciones entre Teutila - Malinche e Iracema: vírgenes y/o madres simbólicas en Xicoténcatl (1826) e Iracema (1865)}

Los personajes, Marina y Teutila, conforman, por su estructura narrativa, un devenir de acciones y de ejemplos: Marina, en la primera parte de la novela es, colocada en el lugar del buen salvaje cuando Ordaz la introduce en la narrativa. Luego, en una segunda fase, el personaje Malinche es mostrado como el ser degradado por las circunstancias que se torna un ente que seduce y corrompe, que engaña y conduce a la perdición, para, en los capítulos posteriores, la última fase, mostrar una evolución ejemplar, desdeñando a aquellos que la corrompieron y mostrando el digno valor de ser madre de una nueva sociedad. 
Teutila, de una manera más simple, representa el valor espiritual más prístino, es la virgen intocable, la obediencia que muestra la ejemplaridad moral, ética y civil, la conducta que, a partir de los actos, hace que Marina se torne una aliada venerable. En ese sentido ambos personajes, por su configuración narrativa, establecen un vínculo y un diálogo con el personaje de una novela brasileña: Iracema de José de Alencar.

De la misma forma que hay una relación dialéctica entre Marina y Teutila para mostrar los valores de una sociedad en formación, en el caso de Iracema podemos entender tres dimensiones; la primera de ellas define a un personaje que, por sus valores éticos y de carácter espiritual, es una guerrera, una sacerdotisa y una virgen, condición fundamental para ser quien preserve el secreto "da jurema", una planta que se consume con un fin de carácter espiritual.

La segunda dimensión es la de una mujer enamorada, alguien apasionado que se entrega a su amante, una amante que se entrega a su pasión, de forma absoluta. Esto define la relación con el personaje Martín, colonizador portugués con quien Iracema establece un vínculo afectivo y espiritual. La tercera fase de Iracema, la describe como una esposa, una madre y una mártir, pues al seguir a Martín y entregarse a él se transforma en la esposa de un guerrero europeo, con el cual tendrá un hijo que nascerá de la tristeza porque, al ser partícipe de una guerra, Martín tiene que abandonar a Iracema y, al regresar, descubre que está muriendo, lo cual, la torna una mártir.

Por otro lado, Marina y Teutila son la clave para explicar la tesis de la voz narrativa en Xicoténcatl (1826), y si comparamos el dúo formado estos personajes femeninos, separadamente, con el personaje Iracema en la obra del mismo nombre, obtenemos algunos paralelos importantes.

Teutila e Iracema, ambos personajes totalmente ficcionales, están configurados como las bellísimas vírgenes, como una simbolización de la belleza americana. Mientras que en Teutila se resalta la belleza del autóctono, sin hacer uso de descripciones específicas, con adjetivos específicos para esta, sino exaltando solamente su belleza y pureza, que como máximo se menciona que sus atributos llegan a dejar atónitos a quienes la observan, haciendo que nazca en estos un impulso por poseerla, como sucede con los personajes representantes del europeo, Ordaz y Cortés - lo cual hace que se interprete la intención de poseer a Teutila como simbología de la intención de posesión del continente. 
El lector, sin embargo, observará que la narrativa no coloca descripciones especificando cómo sería Teutila físicamente, como sí lo hace la voz narrativa en Iracema. El personaje Iracema recibe atributos específicos de la voz del narrador, como en el pasaje siguiente: "a virgen dos labios de mel, que tinha os cabelos mais negros que a asa da graúna e mais longos que seu talhe de palmeira [...] O pé grácil e nu, mal roçando, alisava apenas a verde pelúcia que vestia a terra com as primeiras águas." (ALENCAR, [1865] 2010, p. 12).

En ese aspecto, se confirma que la configuración del personaje Iracema, como lo explica el autor en la carta publicada junto a la obra desde la primera edición: “[...] Quando em 1848 revi nossa terra natal, tive a ideia de aproveitar suas lendas e tradições em alguma obra literária. [...] faltava-lhe o perfume que derrama sobre as paixões do homem a beleza da mulher" (ALENCAR, [1865] 2010, p. 108), por lo menos inicialmente, tenía el objetivo de adornar la narrativa con una historia de amor. Por otro lado, se podría decir que Iracema representa la exuberancia virginal de las tierras americanas.

Otro punto interesante para comparar está en que Teutila, desde el inicio de la obra, solo tiene ojos para Xicoténcatl, el joven. En la narrativa, este personaje cuenta cómo le había conocido y cómo fue el proceso que llevó a que se amen. Cuando sucedió esto, ella era la esclava del héroe. Sin embargo, todos los encuentros entre los dos, durante toda la narrativa, son castos, mientras que se aguarda por la esperada boda, sin contar que los dos son separados cuando Cortés mantiene cautiva a la joven "virgen" que no le acepta sus avances.

Ya Iracema es más activa. Ella es la sacerdotisa, guerrera, "virgen" que decide, por libre y espontánea voluntad, unirse a Martín. Este solo percibe que ella es su mujer cuando esta se lo advierte. Desde este ángulo, comparando con el caso del personaje Teutila, como representación de las tierras americanas que todos quieren poseer, en Iracema la natureza se ofrece libre al europeo, sin restricciones. Y además, estará allí para cuando lo necesite, como cuando Iracema salva a Martín diversas veces y después lo espera.

Al contrario de lo que sucede con Teutila, el personaje doña Marina también, al igual que Iracema, simboliza ese ofrecimiento libre. Malinche ofrece todo a su dueño, Cortés, en la narrativa, y lo hace colaborando activamente. En este aspecto, la configuración del personaje de extracción histórica coincide con la de Iracema. La diferencia es que al final de Xicoténcatl (1826) Marina deja de colaborar activamente con Cortés. Desde su decisión de retornar a los valores indígenas, ella solo le obedecerá como la esclava que es. Contrastando, Iracema no 
abandonará su libre disposición ante Martín, el europeo, hasta el final, inclusive cuando llega a morir.

No podemos dejar de recordar que Iracema, de la misma forma que Marina o Malinche, es un personaje esférico, complejo, que evoluciona y representa el proceso de conquista a partir de la reinterpretación histórica y de la configuración estética.

Por otra parte, con respecto a la simbología de convertirse en madre, la narrativa no deja claro cómo Malinche llega a embarazarse de Cortés y lo deja al lector. Lo que sí sucede, es que Marina asume su papel muy bien, pues su transformación final, la que da paso a la configuración de personaje esférica, es alrededor de su maternidad. Con esto, su condición en la narrativa ayuda a explicar, junto a los sucesos con respecto a Teutila, porqué Malinche se convierte en la madre simbólica de la futura nación mestiza mexicana.

Iracema, Teutila y Malinche representan la suma de valores espirituales, morales y civiles que definen, en la literatura del siglo XIX, la reinterpretación de la conquista a partir de la novela histórica. Iracema, de acuerdo con el desarrollo de la novela de Alencar, es virgen, guerrera y sacerdotisa, características que la relacionan con Teutila, ya que, al igual que dicho personaje, Iracema encarna la fidelidad hacia el ser amado y, con ello, la disposición de un personaje esférico; el único, al igual que Malinche, ya que sufre varias transformaciones que la tornan un ser complejo, simbólico y profundo. Es el ente que defiende el valor de su honra como guerrera y el sentido de su amor como esposa y madre. Es heredera del proceso de colonización y, como tal, se mantiene impoluta, digna y firme, caracterizando el amor romántico de una forma mucho más profunda y coherente al morir en una floresta virgen que representa la metáfora de esa composición poética compleja.

En Iracema hay elementos de Teutila, características prístinas que se equiparan con ese personaje al encarnar la fidelidad, y evoluciones complejas que muestran su vínculo con Malinche, ambas, madres que emergen de actos violentos, ambas, dignas representaciones estoicas de los procesos históricos que marcaron el surgimiento nuevas naciones.

\section{Las obras Xicoténcatl (1826) e Iracema (1865): obras madres simbólicas de los proyectos literarios latinoamericanos en el siglo XIX}

Ahora bien, el pensar en las obras Xicoténcatl (1826) e Iracema (1865) como "obras madres simbólicas de la literatura" es pertinente debido a que, ambas, en sus respectivos 
lugares y bajo las perspectivas individuales de sus autores, de alguna manera, son el germen a partir del cual se escribirá en Latinoamérica ayudando a la formación de una "literatura nacional".

Xicoténcatl (1826) es una obra que no consigue fundar, a partir de su publicación, una “escuela" (FLECK, 2017). Mientras que las obras Waverly (1814) y Ivanhoé (1816) de Walter Scott, repercuten de tal manera en el mundo literario que se vuelve moda escribir a la manera de Scott, Xicoténcatl (1826) es una obra que, por sus características, se considera una obra fuera de los modelos de la época y no llegó a tener esa repercusión que tuvieron las obras scottianas.

La obra ochocentista Xicoténcatl (1826) no sigue el modelo de Scott y, al ser la primera novela histórica de México, de Latinoamérica y en lengua española, ya incorpora una postura crítica ante la historia oficial. Al traer a la luz la posible voz de los vencidos, su discurso se muestra crítico del discurso histórico escrito por el colonizador. Esta característica es muy significativa y demuestra que desde temprano en Latinoamérica ya se tenía ese "movimento de desvio da norma, ativo e destruidor, que transfigura os elementos feitos e imutáveis que os europeus exportavam para o Novo Mundo" (SANTIAGO, 2000, p. 18).

Al ser esa "postura crítica" ante el proceso de colonización y al ser considerada como una obra "ochocentista", la novela Xicoténcatl (1816) posee características que la determinan, como una obra que sigue tanto los cánones neoclásicos ${ }^{9}$, como los padrones románticos. En el texto La poética o las reglas de la poesía en general y de sus principales especies (1974), de Ignacio de Luzán ${ }^{10}$, se define la función de la novela a partir de la "perfecta representación de la naturaleza", en la cual, los valores éticos, morales y civiles, deben ser expuestos como

\footnotetext{
${ }^{9}$ Jorge Ruedas de la Serna en su obra Arcadia: tradição e mudança (2006), realiza un estudio comparado entre el movimiento arcádico en Brasil y el mexicano, investigando, de forma profunda, respecto a la influencia de los autores latinos que influyeron en la concepción poética de los poetas anteriores al periodo de la independencia y que, en cierta medida, gestaron un movimiento artístico de carácter original. Para Jorge Ruedas de la Serna (2006) aquello que se define como un canon poético neoclásico, tiene relación con los preceptos desarrollados por Ignacio de Luzán en su Poética (1974), en la cual, el autor define de forma precisa la relación entre la representación del mundo, de forma perfecta y nítida, a la par de las conductas morales ejemplares representadas en los héroes de las obras.

${ }^{10}$ Ignacio de Luzán (1702 - 1754), en su texto La poética (1974, p. 103), va a definir a la obra literaria como una representación de la naturaleza, en donde el creador de una obra, recrea a la misma a partir de la imagen: "Y como de la icástica es objeto la verdad, así de la fantástica lo es la ficción, al modo de la pintura, o representa algún hombre como es, lo que propiamente se llama retratar [...]”. La icástica se refiere a la historia: lo fantástico se refiere a la concepción poética.
} 
modelos de conducta y de perfectibilidad que los lectores deben comprender y seguir, creando con ello una imagen ejemplar, verosímil, pulcra en su concepción narrativa.

Por ello, afirmamos que la obra se encuentra entre dos concepciones poéticas: la ochocentista o neoclásica y la que se encuadra en el primer romanticismo decimonónico. Ya que si bien Ignacio de Luzán (1974) determina, en su tratado de poética, que la realidad debe ser configurada de forma perfecta al recrear la naturaleza y por ello, las nobles acciones de los héroes que prescriban comportamientos ejemplares, en el texto El romanticismo social (2005), de Roger Picard, el autor describe que uno de los primeros objetivos del romanticismo en Europa fue el describir las cuestiones sociales y políticas que mostrasen el compromiso de los artistas por denunciar y señalar las conductas inmorales e innobles de los diversos espectros que se configuraban en las obras literarias, de ahí que la obra Xicoténcatl (1826) configure en la descripción de la conducta de sus personajes, el modelo perfecto de conducta y el discurso ostensible de la ciudadanía modelo, al igual que el compromiso de representar y denunciar las atrocidades cometidas por un pueblo que somete a otro.

Por este motivo, se la considera como el embrión que trae consigo la semilla de la que se convertirá en la Nueva Novela Histórica Latinoamericana - a partir de 1940, con la publicación de El reino de este mundo (1949), de Carpentier - al recontar los sucesos a partir de los que no tuvieron voz en los anales de la historia. Además, los excluidos son configurados como héroes clásicos y el héroe de la Contrarreforma española, Cortés, es mostrado como un bajo villano.

Tal vez no tengamos documentos que confirmen el proyecto literario del autor. Sin embargo, sí se puede observar que el autor esperaba impactar en el público lector con su texto. En primer lugar, calculadamente, publica en lengua española en Filadelfia, Estados Unidos, como autor anónimo, un texto que seguramente podría llevar a la cárcel a su autor en la época. Como confirma Forero Quintero (2012), el contenido crítico de la obra iba a chocar contra autoridades de la colonia española, España y con los Estados Unidos, donde se publica.

Las publicaciones, a partir de Xicoténcatl (1826), no presentarán la criticidad frente a cómo fue contada la historia, pero sí iniciará una producción literaria en México con el tema de los personajes de esta obra, como Teutila (1828), de Ignacio Torres Arroyo, y el drama Xicohténcatl (1828), de José María Moreno Buenvecino, entre muchos otros, todos 
mencionados por Leal y Cortina (1994) ${ }^{11}$. Es, en este sentido, que la obra del autor anónimo, Xicoténcatl (1826) se convierte en alguna manera en madre del proyecto literario de la nación mexicana y de Latinoamérica.

Eduardo F. Coutinho, en el libro Literatura Comparada na América Latina (2003), reflexiona respecto a la pertinencia de comparar obras literarias creadas en América Latina a partir de su composición narrativa para de esta manera comprender el sentido artístico y el carácter ideológico de las mismas. En este sentido, las dimensiones poéticas, estéticas y narrativas de dos obras literarias que reconfiguran la historia antigua de las culturas indígenas en el proceso de conquista, representan la composición de momentos específicos en la formación de identidades nacionales, las cuales, utilizarán la historia, la literatura y el lenguaje como elementos que permiten procurar una originalidad y una identidad.

Por ello, Iracema (1865), como novela, representa una suma de carácter histórico y estético, pues, como lo exponen Laianice Soares Adorno y Amanda Moura de Souza (2019) las Cartas, como respuesta que escribe Alencar a Gonçalves de Magalhães, son una propuesta de alto carácter estético que definió el valor de la literatura a partir de la representación de su historia, su naturaleza, sus costumbres y su reconfiguración de la realidad para crear un proyecto de identidad a partir de un sistema literario, el cual, según Antonio Candido (1975), surge a partir del reconocimiento de una naturaleza, de una realidad social, de lectores que lo reconozcan y, fundamentalmente, de un lenguaje.

Estas cartas en su conjunto son la propuesta poética que coloca al lenguaje, a la naturaleza y a la historia indígena como elementos para crear a un ser con tres dimensiones: Iracema, el cual, dialoga con la concepción de los indígenas mexicanos a partir de la creación de un proyecto literario nacional que representa la metáfora de la complejidad narrativa, ideológica y artística en la cual el indígena se inserta como parte de una reconfiguración histórica.

\section{Referencias}

\footnotetext{
${ }^{11}$ De acuerdo con los organizadores de la versión de 1994, "En 1828 aparecen en Puebla la tragedia en cinco actos Teutila de Ignacio Torres Arroyo y el drama Xicohténcatl de José María Moreno Buenvecino. Al año siguiente, también en Puebla, José María Mangino publica su comedia en cinco actos [con la misma grafía] Xicoténcatl. Las tres novelas son el resultado de un concurso celebrado en Puebla en 1828, concurso inspirado por la novela de Filadelfia." (LEAL; CORTINA, 1994, p. xviii).
} 
ABREU, Mirhiane Mendes de. Ao pé da página: a dupla narrativa em José de Alencar. Campinas: FAPESP, Mercado de Letras Edições e Livraria, 2011.

ALENCAR, José de. "Polêmica sobre A Confederação dos Tamoios". In: Domingos José Gonçalves de Magalhães. A Confederação dos Tamoios edição fac-similar seguida da polêmica sobre o poema. Organizadores, Maria Eunice Moreira y Luis Bueno. Curitiba: Editora Universidade Federal do Paraná, 2007.

ALENCAR, José de. Iracema: lenda do Ceará, Brasil. [3. ed]. Apresentação de Paulo Franchetti. Notas e comentários de Leila Guenther. São Paulo: Ateliê Editorial, 2012.

ALENCAR, José de. Antiguidade da América e A raça primogênita. Apresentação e notas de Marcelo Peloggio. Fortaleza: Universidade Federal do Ceará, 2010.

ALENCAR, José de. Iracema: Lenda do Ceará. Edição do Centenário - 1865 - 1965. Nota Explicativa de M. Cavalcanti Proença. Introdução Biográfica de Brito Broca. Rio de Janeiro: Livraria José Olympo Editôra, 1965.

ANÓNIMO. Xicoténcatl. Prólogo, organização, estudo preliminar e notas de Antonio Castro Leal. [2. ed.]. p. 73-177. In: CASTRO LEAL, Antonio (Org.). La novela del México colonial. México: Aguilar, 1964.

ANÓNIMO. Xicotencatl. Edición, estudio preliminar y notas de Gustavo Forero Quintero. Madrid: Vervuert, 2012.

BARTRA, Roger. La jaula de la melancolía. México: Editorial Grijalbo, 1987.

BECCO, Horacio Jorge. Pensamiento Político de la Emancipación. Vol 1. Prólogo de José Luis Romero ROMERO, José Luis. Selección, notas y cronología de José Luis Romero y Luis Alberto Romero. Caracas: Biblioteca Ayacucho, 1977.

CANDIDO, Antonio. Formação da literatura brasileira: momentos decisivos. 5. ed. Belo Horizonte: Ed. Itatiaia. 1975.

CYPESS, Sandra Messinger. La Malinche in Mexican Literature: from History to Myth. 4 ed. Austin: University of Texas Press, 2000.

DEL POZO GONZÁLEZ, Leila Shaí. Malinche no espelho das traduções de Xicoténcatl (1826): [1999 - 2013]. 2017. 212f. Dissertação (Mestrado em Letras) - Universidade Estadual do Oeste do Paraná, Cascavel.

FLECK, Gilmei Francisco. O romance histórico contemporâneo de mediação: entre a tradição e o desconstrucionismo - releituras críticas da história pela ficção. Curitiba: CRV, 2017.

FORSTER, Edward Morgan. Aspectos de la novela. Trad. de Francisco González Aramburu. Xalapa: Universidad Veracruzana, 1961. 
HENRÍQUEZ UREÑA, Pedro. La Utopía de América. (Caracas: Biblioteca Ayacucho, s.d.)

HERREN, Ricardo. Doña Marina, La Malinche. México: Ed. Planeta, 1993.

JOZEF, Bela. História da literatura hispano-americana. 4. ed. Rio de Janeiro: Editora UFRJ; Francisco Alves Editora, 2005.

LACUNZA, José María. Netzula. In: MIRANDA CÁRABES, Celia. La novela corta en el primer romanticismo mexicano. Estudio preliminar, recopilación, edición y notas de Celia Miranda Cárabes. Ensayo de Jorge Ruedas de la Serna. México: Universidad Nacional Autónoma de México, 1985. 129-151.

LIMA BACA, Francisco. La representación poética del indígena en tres novelas latinoamericanas: Netzula de José María Lacunza; Iracema de José de Alencar y Aves sin nido de Clorinda Matto de Turner. Tesis (Doctorado en estudios latinoamericanos). Universidad Nacional Autónoma de México. México D. F., 2015. pp. 264.

LUZÁN, Ignacio de. La poética o reglas de la poesía en general y de sus principales especies (Ediciones de 1737 y1789) con Las Memorias de la vida de Don Ignacio de Luzan escritas por su hijo. Introducción y notas de Isabel M. Cid de Sirgado. Madrid: Ediciones Cátedra, 1974

MELÉNDEZ, Concha. La Novela Indianista en Hispanoamérica (1832 - 1889). Madrid: Imprenta de la Librería y Casa Editorial Hernando, 1934

NEVÁREZ, Lisa. My reputation precedes me: La Malinche and Palimpsests of Sacrifice, Scapegoating, and Mestizaje In Xicoténcatl and Los mártires del Anáhuac. Decimononica, v. 1, n. 1, p. 67-85. 2004. Disponible en: <http://www.decimononica.org/wpcontent/uploads/2013/01/Nevarez_V1.1.pdf>. Accedido en: 17 ene. 2016.

PAZ, Octavio. El laberinto de la soledad. 4. ed. México: Fondo de Cultura Económica, 2005.

PICARD, Roger, El romanticismo social. Trad. Blanca Chacel. México: Fondo de Cultura Económica, 2005.

RAMOS, Samuel. El perfil del hombre y la cultura en México. México D. F.: Herederos de Samuel Ramos, 2001.

RUEDAS DE LA SERNA, Jorge. Arcadia: tradición y mudanza. México: Universidad Nacional Autónoma de México, Coordinación de Humanidades, 2006.

SANTIAGO, Silviano. Uma Literatura nos Trópicos. 2. ed. Rio de Janeiro: Rocco, 2000.

SOARES ADORNO, Laianice; SOUZA, Amanda Moura de. Cartas resposta ao poema "A Confederação dos Tamoios": uma analogia entre a proposta poética de José de Alencar e a 
poética europeia. Ponencia. XVII SEMALET/ Universidade Estadual de Feira de Santana, 2019.

TOLA DE HABICH, Fernando. Diálogo sobre los “Año Nuevo" y la Academia de Letrán. In.: . El Año Nuevo de 1837. México: Universidad Nacional Autónoma de México, 1996.

USLAR PIETRI, Arturo. El mestizaje y el nuevo mundo. In: Cuarenta ensayos. Caracas: Monte Ávila Latinoamericana, 1985.

VARELA, Félix. Jicoténcal. Edición y estudio introductorio de Luis LEAL y Rodolfo CORTINA. Texas: Arte Público Press, 1994. 